\title{
Changing Perspectives on the Capital Investment Process
}

\author{
William K. Hall*
}

The environment within which institutions undertake commercial and industrial activity changes both as a result of decisions dependent on the institution itself and as a result of decisions independent of the institution. In recent years many of these changes have resulted in changing perspectives on the range of criteria which should be considered when determining how and where large corporations should invest their money. This paper examines these changes in corporate practice and identifies the cumulative results of these changes in the environment of corporate activity. The paper also examines some of the key elements in new approaches which corporations are adopting to capital investment decisions by utilizing data on a broadly based research project which examines in depth the capital investment/ resource allocation processes of five large, worldwide. manufacturing firms. The subject is of vital importance to large and small businesses, both because of the crucial importance of investment decisions and because of the importance for future strategic planning of identifying the environment within which corporate activities take place.

Despitc morc than a half century of thinking and research, the question as to how large corporations should invest their money still remains one of the most challenging issues facing corporate management today. It is obvious that the way in which this question is resolved in practice has a major impact on corporate profitability and performance. Moreover, the effectiveness of this resource allocation process also has major implications for the performance of capital markets and for the contribution of the private sector to a growing number of stakeholders-employees, shareholders, customers and the public-at-large.

There is now growing evidence that large firms have begun to think and act differently with respect to capital investment decisions during the past dccadc.

\footnotetext{
-Graduate School of Business Administration, The University of Michigan. (C) 1978, The University of Michigan.
}

These changes in corporate practice have not been revolutionary; instead, they have been slow and evolutionary, responding to some fundamental, underlying trends in the business environment:

(1) Slower, erratic growth in customer markets;

(2) Limited availability of capital, raw materials, new technology, and managerial resources;

(3) Increased regulatory constraints on product performance and production technology; and

(4) Increased worldwide competition, with firms managed for capital gains competing against firms (and nations) who are primarily interested in employment/ balance of payments gains.

The cumulative result of these four trends has forced progressive firms to add more selectivity and focus to their capital investment/resource allocation decisions. Through increased selectivity, these firms are attempting to concentrate their resources and skills on a more limited set of investment activities, giving up the idea that they should be 'all things to all people'. Through increased focus, these firms are attempting to manage the selected investment activities with precision, finding ways to promote and protect a competitive advantage in an increasingly hostile environment. As a result, traditional financial-based, incremental approaches to resource allocation decisions are being supplemented or even replaced in many corporations.

The purpose of this paper is to examine some of the key elements in these new approaches. The data came from an ongoing research project into the general management process in large, complex corporations, and the conclusions are based upon indepth examinations of the capital investment/resource allocation process in five large, worldwide manufacturing firms. The paper will first examine the traditional view of capital expenditure analysis and then discuss the new revisions and alternatives as they are currently being implemented. 


\section{The Traditional View}

The traditional view of capital expenditure analysis grew out of the microeconomist's theory of the firm and theory of investment in the 1930s. Refined by applied research at schools of business administration and by application in a large number of corporations, this approach was based upon several observations:

(1) That the relevant costs and revenues for evaluating a capital investment project are the incremental costs and revenues resulting from implementation of the investment decision;

(2) That these relevant costs and revenues should be combined to project the incremental cash flows flowing to and from the investment over the project's life; and

(3) That those investments whose discounted net present value (at the firm's total cost of capital) exceeds zero will increase the value of the firm (to the shareholders).

In terms of the neoclassical theory of the firm, there is little argument that this view of the investment process is correct, and much work was done during the late 1960s to refine it, using computer models and probabilistic risk analysis. Further sophistication in the approach was added in the early 1970s, tying capital investment decisions to the market performance of the firm's equity, using the capital asset pricing model and related theoretical concepts.

The problem comes, however, when one tries to 'operationalize' this approach in making real capital expenditure decisions in complex, multiproduct, multilevel corporations. In this environment, forecasts of incremental costs and revenues are made in an environment of great uncertainty, and risks relevant to the project's success are frequently' impossible to quantify. ${ }^{1}$ As one chief executive officer interviewed by this author pointed out,

\footnotetext{
The unforeseen event will occur again, just as the oil embargo of 1973 and the worldwide recession of 1975 . . And no econometric model or economist has the power to accurately forecast such uncertainties ... despite our use of increasingly sophisticated tools, it's still a lot like rolling dice.
}

Moreover, investment decisions in this uncertain, rapidly changing environment have a sociopolitical dimension which is at least as great as the economic dimension. This sociopolitical dimension arises out of the fact that resource allocation decisions in the large firm are not made by a single, omnipotent individual performing analyses and making decisions. Instead the resource allocation process involves a complex web of interactions among different organizational levels, different functions and different people. Since the 'actors' in this web possess different information and different objectives, any attempt at concensus invariably results in the limited consideration of investment alternatives and biased financial analyses. Consider, for instance, the following statement by a senior corporate officer:
The danger of incremental cash flow analysis is that it invariably leads you to make the next round of investment ... somebody can always stand up and make a convincing case to justify how the incremental revenues for his pet project support the incremental investment.

The following quote by a divisional general manager is even more graphic:

When a project comes in at an estimated 50 per cent return, we cut the estimate down ... the figure might go out (for corporate approval) at 30 per cent ... And this practice works the other way too. Although a (recent) project looked like 8 per cent on paper, I put it through at 12 per cent ... And we haven't had a capital expenditure request rejected in 8 years. ${ }^{2}$

In this environment it seems apparent that the analytical power of a tool like discounted cash flow analysis is far less significant than the managerial power which can be employed to get the relevant investment alternatives generated, approved, and properly executed in a complex organization. Modern views of the investment process are coming to recognize that this managerial power can be either substantive or contextual:

Substantive Power: Power to influence the nature and content of information incorporated into the capital investment dccision process.

Contextual Power: Power to influence the nature and content of the managerial structure and systems (organizational, measurement and reward) within which investment decisions are made.

Moreover, this managerial power can be possessed at a number of levels within the firm, by the corporate management, corporate staff, group or divisional (integrating) management, divisional staff, or middle (functional) management. For example, in one large firm studied by this author, the middle managers in marketing and manufacturing possessed most of the substantive power for facility investment decisions. As a result, they were able to initiate analyses and control the alternatives which were subjected to detailed scrutiny. In this same firm, the corporate staff possessed most of the contextual power through their tight control of expenditure budgets and through the divisional measurement and reward system which they had developed. Interesting enough, top management in this same firm was left with very limited power to influence the investment process, other than their ability to place key people into the line and staff organizations. As a result, after playing 'devil's advocate' with large investment projects submitted to them for approval, they approved almost all decisions within the limits of an aggregate capital expenditure ceiling (as imposed by the corporate staff). The result was a fairly 'even' allocation of capital across divisions, geographic markets, and functions; an allocation that left people happy in the short run but profits down in the long run.

To summarize, the argument being created here is twofold:

(1) The capital investment process in large firms today is more dependent upon managerial power than it is 
upon the analytical power of new tools and techniques.

(2) This managerial power has three dimensions:

(a) The substantive (information) content;

(b) The contextual (structure/systems) setting; and

(c) The organizational levels at which these substantive/contextual decisions and tradeoffs are made.

We shall now proceed to discuss some ways in which these dimensions are shifting as large firms attempt to bring focus and selectivity back into their resource allocation processes.

\section{Modern Views}

In analyzing these changing perspectives toward the capital expenditure decision, the first major finding is that the types of substantive inputs used in allocating resources have shifted. The incorporation of more information than simple forecasts of incremental costs and revenues is being done in most firms (including all five in this study) to shape both the type of alternatives being considered and the way in which these alternatives are being evaluated.

In three of the firms studied by this author, the 'project by project' approach to resource allocation had been displaced by a strategic approach. In these firms, detailed business-level strategy statements were used to focus important investment decisions, while ruling out others that didn't fit the stated business strategy, regardless of their 'paper profitability'. As one chief planning officcr commented:

Allocating resources to investments without a sound concept of divisional and corporate strategy is a lot like throwing darts in a darkened room.

\section{Another CEO supported this view when he observed:}

You don't do things because they meet your financial analysis criteria ... you do things because they are central to your strategy. At best, financial analysis can help you understand the strategic issues better, or force you to go back to your people and tell them the project must be executed better to get an acceptable return.

In the above three firms and in two others, additional information on competition and product/market positioning was inputted into the analyses. The objective of this market-oriented approach was to focus attention on market segmentation and on ways of using scarce resources to promote or protect a long-term competitive advantage with a segment. In these firms, market share and projected market share growth rates were as important in evaluating projects as discounted cash flow ROI. It was the opinion of thesc firms that long-term product/ market position would give long-term capital gains, a concept with some recent empirical support. ${ }^{3}$

The question which must be raised, of course, is where these substantive inputs can (and should) come from.
The traditional view of the decentralized organization suggests that they should originate at the divisional or business unit level. Corporate management, as the argument goes, has neither the time or expertise to input substance into the decision process. In fact, however, corporate management made significant substantive inputs into the investment process in three of the organizations selected for indepth study, once through the corporate staff and twice through the CEO himself:

(1) In one organization the corporate planning staff performed the competitive analysis and then categorized the firm's businesses into strategic classes for investment analysis. Business unit managers were then told to evaluate their investment projects using these corporate analyses and characterizations.

(2) In another organization, the CEO himself identified the key issues and (through a special taskforce) conducted most of the analysis on a major strategic investment. In his opinion, personal reinvolvement in the substance of the resource allocation process was essential to promote the firm's strategy at the particular time of study.

Thus, based upon the limited samples selected for indepth study in this research, it would appear that new types of substantive inputs based upon strategic considerations are dominating the classical financial inputs into the resource allocation process. Moreover, it would appear that these substantive inputs are coming from higher levels of the organization, involving both corporate management and corporate staff. This latter observation represents a major shift from the 1960s, when corporate functions came to be viewed as primarily 'administrative' and 'integrative' through the establishment of context.

How then, one might ask, has contextual power shifted in the late 1970s? One major change in two of the organizations under study involves the establishment of 'strategy centers' or 'strategic business units' ${ }^{\text {f }}$ for the purposes of resource allocation. In these organizations, the measurement and reward systems for individual strategy centers are being adopted to fit the particular role the centers are supposed to be playing within the overall corporate strategy. As such, the context is being tailored to promote certain kinds of investment projects, while filtering out other types of proposals. For example, one firm in the sample chose to measure a particular strategy center on short term cash generation; using this criterion, the firm has been able to promote cost cutting investments in the division while discouraging new business ventures, a pattern of resource allocation consistent with the divisional and corporate strategy.

A second contextual change in four of the five organizations has been the movement away from rigid, 'MBOish' goal-setting downward through the firm. Instead, corporate and divisional goals are enunciated and communicated in broad, strategic terms. Within these expansive, top-down strategic guidelines, operating managers are expected to execute investment projects selectively, focusing their group or divisional resources 
on projects where they can find and maintain a competitive advantage. The common desire in these firms is to force strategic thinking downward, while adding stronger 'strategic controls' to monitor performance at the corporate level. Specifically, the attempt has been to add a strategic orientation to the management process, supplementing the traditional operational orientation imposed by rigid goal-setting and budgetary controls, an attempt which lends support to Quinn's recent study: ${ }^{5}$

Effective top executives in larger enterprises typically state a few broad goals ... They eschew the gimickry of simplistic 'formal planning' or ' $\mathrm{MBO}$ ' approaches for setting major goals . . . Instead they tend to develop such goals through very complicated, largely political, consensus-building processes that are outside the structure of most formal management systems.

The third contextual change noted in this study is change itself. All five organizations made one or more significant structural shifts during the period of observation, even though only one shifted corporate strategy during this period. Two adopted the 'management committee' approach to the organization of their executive offices, with the rationale in both cases based on the need for stronger evaluation and co-ordination of operating units and on stronger strategic planning. One added a new corporate staff group directly responsible for strategic planning (two others had added such a staff in the early 1970s). Moreover, three firms in the sample consolidated related divisions and functions into more focused groups directed by senior officers. In all three cases, this group structure was designed to consolidate, co-ordinate and focus divisional plans and to reduce the span of control of executive officers, freeing their time to work on externalities and broad policy issues. ${ }^{6}$

In all of the structural shifts observed, the common attempt was to obtain more focus and strategic inputs to the resource allocation process, while attempting to avoid the overcommitment of top management resources to this process. Interestingly enough, all of the firms projected further corporate re-organizations as they experimented with substance/context tradeoffs at various management levels. As one senior officer commented,

Complexity and change will force most well managed companies to live in semi chaos for the next few years . . organizational stability will be an accident, as these firms continually try to outstretch and out maneuver their competition.

\section{Summary}

The purpose of this paper has been to examine changes in the resource allocation process as large, complex organizations attempt to bring strategic focus and selectivity to this process. Based upon the preliminary evidence obtained in this examination, it would appear that:

(1) Strategic criteria are displacing traditional financial criteria as the driving mechanisms behind the resource allocation/capital investment process;

(2) Corporate managements are experimenting with new concepts and with new substance/context tradeoffs at corporate, divisional, and middle management levels as they attempt to balance their strategic needs with external opportunities and uncertainties.

Since it appears likely that these experiments will continue into the 1980s, it is essential for general management researchers to become more involved in process research, to ensure that the experiments are properly executed, but more importantly, to ensure that generalizations and interpretations are properly assessed and disseminated. There is little question that the 'name of the game' is changing in corporate practice, and patterns of management research must change too in order to meet managerial needs of the decade ahead.

\section{References}

(1) See, for example, W. K. Hall, The uncertainty of uncertainty in business planning, Managerial Planning, 23 (2), 7-12 (1974).

(2) Taken from Basic Industries, Intercollegiate Case Study, No. 6-313-121 (1971).

(3) See Buzzell and Sultan, Market share-a key to profitability, Harvard Business Review, p. 97 January-February (1975).

(4) See the article by W. K. Hall, SBU's-hot, new topic in the management of diversification, Business Horizons (Winter 1978).

(5) J. B. Quinn, Strategic goals: process and politics, Sloan Management Review, pp. 21-37 (Autumn 1977).

(6) For a related approach to such group structures, the reader is referred to the 'sector' management approach recently implemented by General Electric, GE's new billion-dollar small businesses, Business Week 19 December (1977). 